\title{
The Peculiarities of Frigyes Hidas's Style of Wind Music
}

\author{
Josef Csikota ${ }^{1, *}$ Galima Lukina ${ }^{2, a}$
}

\author{
${ }^{1}$ Orchestra University, Mako, Hungary \\ ${ }^{2}$ State Institute for Art Studies, Moscow, Russia \\ aEmail: galima96@list.ru \\ *Corresponding author.Email: csikotaj@csikotajozsef.hu
}

\begin{abstract}
The article focuses on the style of the creative work of Frigyes Hidas (1928-2007), a Hungarian composer, who had significant influence on the development of orchestral wind music in Hungary. His artistic legacy has not been yet thoroughly studied by musicologists, which determines the relevance and topicality of the subject of the article. The authors attempt to understand the origin and displays of Frigyes Hidas's romantic focus, as well as his craving for "simplicity", which fits into the "new sincerity" and shift from the "new complexity".
\end{abstract}

Keywords: Frigyes Hidas, Hungarian music, orchestral wind music, style, "new simplicity"

\section{INTRODUCTION}

Frigyes Hidas is a distinguished contemporary Hungarian composer. He achieved worldwide recognition due to his compositions for wind instruments and wind orchestra. Composing at least one musical piece for each instrument of wind orchestra was his life goal. He created solo and ensemble concertos, duets, trios, quartets, octets, compositions for chamber and concert wind orchestras, having made an important contribution to the development of the performing culture in Hungary.

The composer's creative career was considerably influenced by the events of the Hungarian musical life in the second half of the 20th century. In the postrevolution time (after the revolution of 1956 and the cultural and political revolution of the 1960s), the revival of the banned Bartók's music, the emergence of the Hungarian avant-garde, experimental music and New Simplicity were made possible, as well as the establishment of the New Music Studio, Group 180, and the Dance House Movement, etc. ${ }^{1}$ Such was the cultural context for Hidas to develop his artistic language, which is most precisely described by the concept of "new simplicity" 2 . His ambition was to write music that would evoke positive feelings and connect people by means of the power of its melody, harmony and rhythm; music that would be understood by the mainstream audience and, therefore, "people would smile, while listening to it" (according to Hidas's radio \footnotetext{
[2], [3], [4]

For the details on Hungarian music life, see references [1],

2 For the comprehension of the "new simplicity" in 20th century music, see A.N. Gracheva [5], N.P. Ruchkina [6]
}

interview). These attitudes formed his creative identity - "the last Hungarian romantic composer" [7].

\section{CREATIVE ORIGIN AND PREFERENCES}

As Frigyes Hidas's creative biography shows ${ }^{3}$, the key factors behind his composer formation were his service as an organist (before starting the Academy of Music in 1946) and a conductor at the St. Stephen's Basilica (1957-1962), his work as an orchestra conductor and the director of the National Theatre in Budapest (1951-1966) and musical directorship of the Budapest Operetta Theatre (1974-1979).

Church service cultivated young Frigyes's taste for culture that preserves the traditions of the great composers of the past. The performance of organ music revealed his outstanding talent for improvisation and contributed into the development of his instrumental thinking. Moreover, the sound of the organ inspired Hidas to search for the inflections of the organ timbre in the music of wind ensembles and orchestras and to compose organ music. The sound of the organ - the instrument to educate his ear to music - significantly affected his key principles of orchestration. The focus on the powerful sound of the organ defined the instrumentation of Hidas's wind orchestra. The result of the orchestra group expansion at least up to four instruments each was that according to the number of performing musicians, the wind orchestra that Frigyes Hidas was writing music for, was almost the size of a symphony one. One of the authors of the present article is a member of the composite author. See: [8]. The book includes biography and memories. 
The years spent working in the theatre helped Hidas understand what music is suitable for a theatrical performance and how the two areas of theatre and music can complement each other. Not only was this theatrical experience advantageous when implementing his ballet and opera ideas (The Cedar ballet, Coriolanus ballet based on Shakespeare's tragedy, The Undanced Ballet $^{4}$, The Woman and the Truth opera, Bösendorfer, etc.), but it was also valuable when composing music for numerous television and radio plays (The Prince and the Pauper, Vasili Tyorkin, Oedipus Rex, etc.) and films (The Danube Pilot, Hungarian Abduction, Fools of Love, etc. $)^{5}$.

Theatre could not but have an impact on the composer's individual music style, which is characterised by realistically built images and almost audio-visual expression. The analysis of Hidas's compositions reveals that the drama of most of his opuses develops according to a certain fabula. Its idea can be indicated in the title of the composition (often it is based on eponymously named literary piece of writing) or it can be made clear in the history of its creation. As if following the laws of ballet divertissement, Hidas's major works of music are founded on the principle of generic contrast and juxtaposition, and the alternation of episodes of the composition. Juxtaposition of multi-genre elements results in either their synthesis or, more commonly, in the establishment of a different quality. Embracing the kaleidoscopic character of the composition becomes possible due to the primacy of the symphonic continuity principle.

\section{STYLE CHARACTERISTICS}

The uniqueness of Hidas's style and the nature of his innovativeness result from the bright combination of the traditional and widely acknowledged (a consonant scale, typical musical structures, the principle of continuity) and the original (the interpretation for wind orchestra, polystylistic methods, interpretation of primary generic models). Hidas characterised himself as a "conservative" composer [10]. It is only his music for films and television plays, which is classified as contemporary culture; the rest of his artistic heritage represents the genres of past centuries, including the Baroque era (Prelude, Passacaglia and Fugue, fantasy and fugue, baroque concerto, suite, cantata, oratorio) and classicism (concertos for solo instruments, ensembles, symphonies, ballet). However, he defined himself as a romanticist, which is substantiated by the cultivation of thematic invention, craving for

\footnotetext{
The score of The Undanced Ballet is analyzed in a separate article by one of the authors. See [9].

The list of films with Hidas's music is available at https://port.hu/adatlap/szemely/hidas-frigyes/person-20755
}

programme symphonic style, and searching for new timbre sounding.

Frigyes Hidas was the first modern composer to realize the variety of timbre and technical capabilities of concert wind orchestras. Experimenting with the instrumentation of the orchestra, he exceeded the scope of the traditional concept of concert composition. He instrumentally interpreted numerous genres, for example, concert compositions for solo with wind orchestra. Even more interestingly, for solo interpretations he chooses instruments that are not typically accompanied by wind orchestra, namely, a violin or a cello.

In his major compositions for wind orchestra, such as the Second Concerto for Flute and Wind Orchestra (1985), Festive Music (1985), The Undanced Ballet (1996), Concerto for Wind Orchestra "Vjenne" (The History of Vriezenveen, 1999), Coriolanus ballet based on Shakespeare's tragedy (1980), Hidas makes the most of the dynamic capabilities of wind orchestra - from the almost pitchless to maximum "tutti forte"; in the scores clearness is combined with the subtle and picturesque orchestral style. The composer refers to visual expression as a colourful means.

\section{CRAVING FOR ROMANTICISM}

Hidas's creative activity represents the whole range of typically romantic means and related images. Unlike many masters of the 20th century, Hidas did not appreciate atonal experiments, could not reject the tonal hierarchy and was guided by the mode and scale variety. The scores of Hidas abound in complex integrating structures and multi-component dissonant fusion, which can hardly be found in the compositions by the immortal creators of the 19th century. Despite all the complexity of the harmonic vertical structure, the development of the intonational forms falls into tonal patterns with the major or minor consonance being the core element of the harmonic system.

In the musical drama of Frigyes Hidas's compositions each intonation performs a certain function being a carrier of a metaphoric idea. Thus, in order to reveal the semantic characteristics of the contemporary Hungarian composer, it is essential to make reference to the composers of the previous generation. Hidas borrowed the most typical and characteristic of their expressive means, however, the borrowing is more a stylization dissolving in the style archetype.

The correlation of the author's and the borrowed is largely guided by the opposition: central (relief) peripheral (background). In other words, original composer's ideas often fall into the context of romantic means (by which we mean harmony, the methods of 
material development) and shape an integral intonation form.

This can be illustrated by Allegro, the concluding and most virtuoso part of The Second Concerto for Flute and Wind Orchestra, where the main, original, brightly designed flight theme in tarantella time ("Fig. $1 ")$ is characterized by a number of romantic parameters. The features to make distant style allusion are the melodic whirling of the theme and the developed repetition of the initial elements: the melody seems to spiral upwards, unable to escape the spiral.

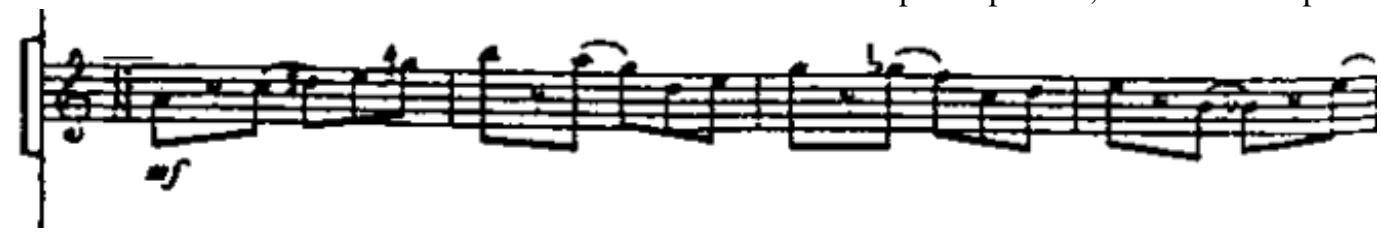

Fig. 1. The Second Concerto for Flute and Wind Orchestra. Part III, Allegro. M. 15, 44.

It is not only the "restless whirling", which conveys anxiety, but also the triplet feel. The author's baseline is indicated by the intonational change of the theme.

The methods of theme development are rather traditional: selecting the motif, sequencing, undulating evolution, polyphonic techniques of work (most frequent in Hidas's work). In a similar way, the author of a flute concerto developed most of his themes, continuing the traditions of the great rather than being an innovator.

One of the most vivid intonational expressions referring to the romantic era is the monologue of the bass clarinet "Vjenne" in the Concerto for Flute and Wind Orchestra ("Fig. 2").

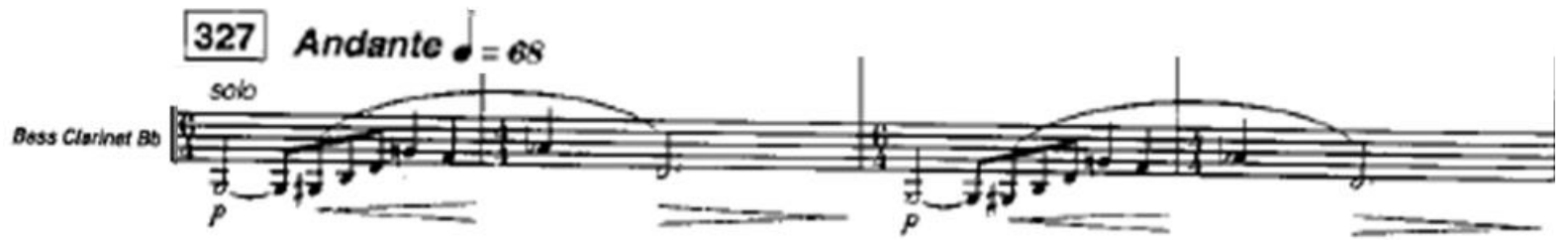

Fig. 2. Concerto for Wind Orchestra "Vjenne".

The mournful interrogative intonation may be narrative of the difficult episodes in the history of the Dutch settlement of Vriezenveen. This hypothesis can be supported by the fact that it was composed to the order of Arnold Span, the conductor of the Harmonie van Vriezenveen orchestra. The request was to narrate through musical means not only the life of the village, but also the difficult times when in the 20th century, its musical ensemble ceased to perform due to two world wars. Therefore, the composition comprises a range of dramatic and tense themes, one of which being the bass clarinet one.

The dissonance of this intonation is ensured by false relation, minor second and major seventh intervals, movement through the sounds of the diminished triad and the descending diminished fifth. General interrogation and tension are created by changing the time (6 / 4-4 / 4), harmonic irregularity and the sequence of the second and the diminished fifth (in the descending direction), typical for romanticists. Additionally, the timbre of low and monological sounds of the instrument enhances the overall sombre impression and reminds the listener of the well-known themes of the romanticists' time.
Another illustrative example of Hidas following the traditions of romantic composers is the introduction theme in the Festive Music for wind orchestra (1985). The title itself puts the listener in a certain frame of mind - they expect the fanfare hymnal theme. Instead, they hear a mournful low register melody by the bassoons and tubas (including tenor tuba). The melodic line communicates a special semantic code with the reference to the typically romantic intonation. Similar formulas in various connotations are often found in thematic compositions by Chopin, Liszt, Schumann, etc.

The themes of the Coriolanus Ballet music for symphony orchestra based on the famous tragedy by Shakespeare should also be highlighted as a characteristic of the romantic era. The music was created in 1980, and the score was published in 1997. This composition is likely to be one of the most contemporary ones, according to the expressive means applied by Hidas. Unlike other wind scores, the Coriolanus scores are dominated by dissonant vertical structure, formed as the result of the fusion of independent melodic lines, sometimes producing the sonorous sound effect. 
The applied expressive means serve to enhance dramatic images, one of them is the theme based on Hidas's favourite interrogative and mourning elements (M. 91). Its intonation is punctuated, which is another technique typically employed by Frigyes Hidas. The dialogical structure itself does not necessarily mean stylistic allusion that refers to romantic opuses. The key role is played by the intonation contour, which embraces minor second intonations and irregular tritonic elements triggering vague associations with the lyrical themes by Chopin and Schubert.

Having appeared in the dissonant context, the romantic theme starting with the lamentable sounds of oboe loses its original interrogative and lament intonations, as they fade in the wind fanfares (meno mosso). Meanwhile, it is precisely the echoed theme that undergoes transformations.

Such is the composer's style of Frigyes Hidas - to provide a vivid detail characteristic of the previous era and immediately emphasize its relation with the present.

\section{FOLKLORISM}

Folkloristic intonation is an equally important stylistic source for Hidas's music. What it involves it is not as much the author's interpretation of Hungarian folklore, but addressing the folk song theme of different peoples, should it be integrated oriental expressions, African American rhythms (blues, jazz), or Slavic intonations.

Thus, in the first part of the Concerto for Wind Orchestra "Vjenne", there appears a theme, which in all respects, including the melodic, harmonic and rhythmic ones, is very similar to Russian long songs. For this reason, if one does not know its author, they can assume it to be the work by Russian composers (The Mighty Five, Tchaikovsky, Rachmaninoff or Sviridov).

It has already been mentioned above that the opus was composed to order and intended to convey the idea of the life of the Dutch village by means of musical instruments. Not sticking to the Dutch folk tune style, Hidas created a general folk theme, with the result being more Russian, than Dutch.

It is supported by the very intonation of the deep and melodious clarinet tune, the timbre of which (out of all the winds) most resembles the human voice ("Fig. 3").

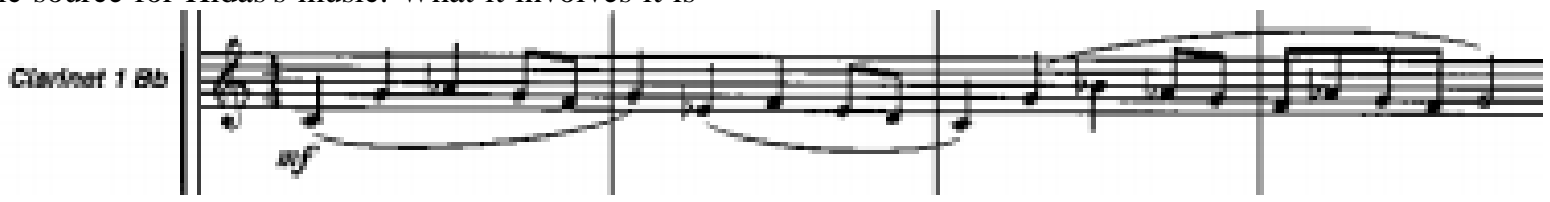

Fig. 3. Concerto for Wind Orchestra "Vjenne", Part I.

The unhurried narration of the theme is particularly characteristic of Russian long songs. There is one more distinguishing feature: when evolving, the ambitus reaches the minor seventh - the interval that is entirely typical of the specified genre. One may recall such masterpieces of folk song lyric as "Yzh, Vy Gory, Vorobyovskiye" [You, Vorobyovy Gory] (Moscow Region), "Vechor Pozdno Bylo Vvecheru" [It Was Late in the Evening] (Krasnoyarsk Krai), "Uzh Ty, Step Li, Moya Step" [You, Steppe, My Steppe] (Voronezh Region) and many other long songs.

The features traditional for long lyrical songs also include monothematic introduction, changing reference tone, tertian second voice, and polyphonic sub-vocal development. Depicting the further events that destroyed the life of a peaceful village, the theme gradually changes and sounds irregular and tense due to the introduction of dissonant complexes. Meanwhile, the integrity of the original melodic line remains, which illustrates not only the implementation of generic elements, but also of the typical for lyric songs development method.
Another theme, contrasting with the one having Russian song folklore origins, is a dance tune theme $(\mathrm{m}$. 63 ), the intonation of which refers to the verbunkos style with the characteristic augmented seconds, punctuated rhythmic formula, and bass ostinato. Thus, Hidas followed Béla Bartók's tradition, but, unlike him, did not intend to modernize the folkloristic means of expression. On the contrary, Hidas treats folk intonations with respect, as Western European romanticists and Russian the Mighty Five did.

However, in some of the compositions, Frigyes Hidas freely and naturally uses folklore elements, for instance, in one of his most frequently performed opuses - the Second Concerto for Flute and Wind Orchestra. Already in the first statement of the flute theme ("Fig. 4"), some general oriental characters are brought into focus: primarily, the ornamental melodic and rhythmic pattern and the modal harmonic foundation, based on one of the variants of semitonic pentatonic scale. 


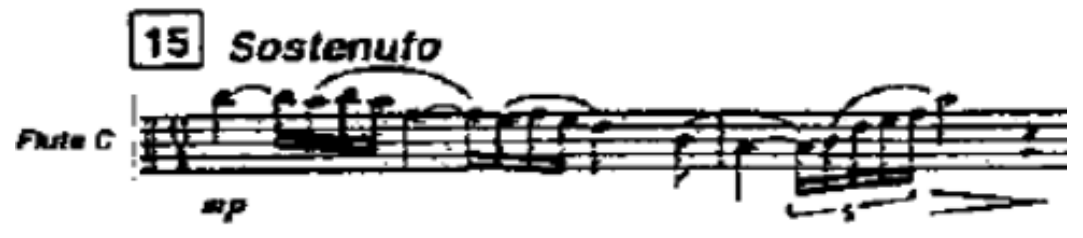

Fig. 4. The Second Concerto for Flute and Wind Orchestra. M. 15

However, with the development of the theme, such stylistic characteristics are found that associate with Slavic melodiousness rather than with the Asian one. This is primarily due to the initial pentatonic series being replaced by a natural tone (m. 13). It is also important to highlight that the mode transformation, which ensures the generic shift in Hidas's compositions, can be implemented through gradual "Europeanization" and vice versa.

There are some shifts according to the logic of crescendo drama: the initially diatonic melody, close to folklore in its style, sophisticates while developing with the introduction of dissonant elements, integrating concordant structure or replacing the traditional for folk music modality with a chromatic mode.

Focusing on the folklore intonation sources in the creative work of Hidas, we should emphasize the oriental folk tunes. What is meant is not only the author's application of the generalized oriental themes and images (in this respect, following the tradition of the Mighty Five representatives, again), but also reinterpretation of the typical Hungarian intonational elements.

Orientalism in Hidas's work is characteristic of both the themes with the clearly perceived folklore generic code and barely folkloristic themes. Additionally, the fusion of augmented seconds is not always indicative of general eastern origin; it sometimes can illustrate the similarity to mode specificity of Hungarian tunes, which are based on the "Hungarian gamut" (the term by I.V. Sposobin) ${ }^{6}$.

The application of certain typical folk music codes, rather than quoting folk sources is the main method of Hidas's work with folklore material. Nevertheless, the constant introduction of typical folkloristic intonations into the musical fabric is organic to the modern

\footnotetext{
6 This modalism was widely practiced in the music by of romantic composers, F. Liszt in particular (in Hungarian Rhapsodies, Sonata h-moll, the symphonic poem The Battle of the Huns). Other remarkable examples of the use of the Hungarian gamut are the opera Carmen by G. Bizet in the fate motif (for the first time in Overture), and Mazurka B-dur op. 7 No. 1 F. Chopin (episode in bars 45-52).
}

Hungarian musical culture, the foundation of which was laid by Béla Bartók and Zoltán Kodály.

\section{POPUlarism VS NEW SINCERITY}

The third stylistic component that we focus on refers to another cultural layer that does not often attract the attention of masters of the academic music genres. It is the connection between the intonational structure of Frigyes Hidas's compositions and the genres of so-called popular music: pop-jazz music and most notably the intonations of early Hollywood films and musicals. Apart from popular song intonations, it is essential to stress the elements of jazz harmony and rhythms that appear in Hidas's scores as a stylistic superstructure rather than as a basis. They often undergo symphonic and polyphonic transformations inspired by romantic and post-romantic composers.

Hidas is largely guided by Hollywood tradition (some of the themes of his compositions resemble soundtracks to old American films), musicals and, of course, individual stylistic elements of sympho-jazz. Thus, in Concerto for Wind Orchestra "Vjenne", in the context of a military march, there appear the features of pop-jazz, reminding the listener of the well-known scores by Leonard Bernstein and George Gershwin. The elements of jazz stylistic introduced into the fanfare and march, influence the subsequent development of the main song (diatonic) theme of the concerto.

A representative example of the appeal to the mass pop-jazz is found in the score of The Undanced Ballet. The elements of the main song and dance theme composed in the style of Hollywood musicals make the listener recall a number of formerly popular melodies from the films and musicals: Singin' in the Rain (by N.H. Brown, 1952), Funny Girl (by J. Styne, B. Merrill, 1968), "42nd Street" (H. Warren, 1933), "Oklahoma" (R. Rodgers, 1943), etc.

Despite the specified stylization, Hidas created an original theme, which he gradually developed in the hymnal part Sostenuto. ("Fig. 5") 


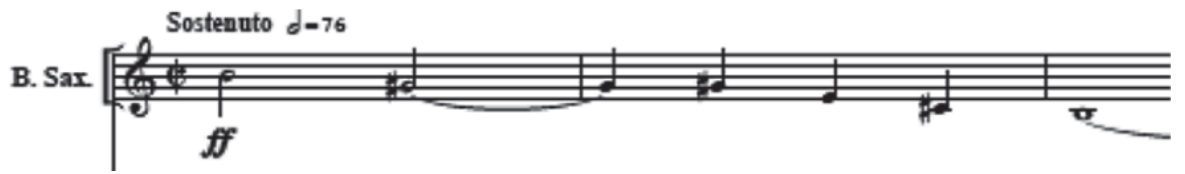

Fig. 5. The Undanced Bellet. Movement I.

The impression is produced that the composer rejects "novelty" in favour of the familiar and understandable, as well as the principles of postmodern irony and cynicism in favour of sincerity as the main motif. There Hidas comes into contact with the artistic trend of "new sincerity", representatives of which aimed at recovering "lost purity" and addressing the problems of "a non-exclusive person in a non-exclusive state" [11].

For these reasons, both experienced and amateur orchestras are attracted by Hidas's compositions. Hidas also transcribed other composers' works for wind orchestra; his name is associated with the famous orchestration of "Rákóczi March" by F. Liszt. His versions for different instrumentation and performance provide new opportunities for musicians and make music accessible to the wider audience.

\section{CONCLUSION}

In Hidas's creative laboratory, all the applied components from different eras and trends are aimed at creating a unique synthesis to preserve the beauty of the sound and the clarity of development principles.

The composer's focus on past in the present corresponds to the shift characteristic of many composers of that time - the shift "from complexity to simplicity of the expression". The "simplicity" of Hidas's music fits into the so-called "new sincerity", "neo-romanticism", and shifting from "new complexity". The original style of the Hungarian composer is still up-to-date, his compositions are widely-known, and unlike many other opuses by his contemporaries, they are still performed in concert halls. This must be the sign of true recognition of the artist's mastery - their creations continuing to attract new generations of musicians and the mainstream audience.

\section{References}

[1] J. Csikota, "Development of Musical Culture in Hungry in the 20th Century" in: "Proceedings of the 2017 International Conference on Art Studies: Science, Experience, Education" (ICASSEE 2017) ("Advances in Social Science, Education and Humanities Research" (ASSEHR)), Atlantis Press, 2017, pp. 23-28.

[2] K. Komlós, "Contemporary Hungarian wind chamber music" in: "Music", 1977, no. 20/4, 47 p.

[3] Yu. Galieva, "Hungarian instrumental music of the second half of the 20th century: the issues of the musical language, form and genre", Author's abstract, Moscow, State Institute for Art Studies, 1995, $20 \mathrm{p}$

[4] B. Szabolcsi, "The history of Hungarian music", Budapest, Corvina, 1964

[5] V. Grachev, "The music of A. Pärt and V. Martynov: the perspective of a new style in the Christian tradition", Moscow, 2016.

[6] N. Ruchkina, "The "New Simplicity" in the musical art of the 20 th - beginning of the 21 st century" in: "Observatory of Culture", 2017, vol. 14, no. 3, pp. 322-329.

[7] Yu. Galieva, op. cit.

[8] E. Saarela, L. Marosi, J. Csikota, R. Hobe, "Hidas Frigyes", Amicus Auctoris Musikverlag, 2014, 130 p

[9] J. Csikota, "The principles of the drama of The Unmanaged Ballet by Frigyes Hidas" in: "Artistic Education and Science", 2018, no. 1 (14), pp. 14-19.

[10] E. Saarela, L. Marosi, J. Csikota, R. Hobe, "Hidas Frigyes", op

[11] D. Prigov, "New Sincerity" in: "Glossary of the Moscow Conceptual School", 1999. 